ISBN 978-93-84468-86-6

2016 International Research Conference on Social Sciences, Humanities and Interdisciplinary Studies

(RCSSHIS-2016)

Pattaya (Thailand) Dec. 16-17, 2016

\title{
Marketing Mix Influencing Consumer Behavior in Choosing Skin Care Clinic at Chularat Hospital 1bangkok
}

\author{
Dr. WatcharaYeesuntes, and Ananya Sanyotha \\ watchara.yee@kbu.ac.th \\ Post Graduate School of business administration, Kasembundit University, Bangkok
}

\begin{abstract}
The purposes of this study were to determine marketing mix and Influencing consumer behavior in choosing Skin care Clinic at Chularat Hospital 1. The samples were selected from 103 customers who were former customers of Skin care Clinic at Chularat Hospitall by using a check list and rating scale questionnaire as a tool. Statistical application used for data analysis was percentage, mean, standard deviation, Chi-Square, and regression analysis.

On the basis of the results of this study, it could be concluded that most of respondents were females, age between 31-40 years old, private companies' workers, bachelor degree graduated, average monthly income 10,000-20,000 baht, most services which received from the hospital were cosmeceutical medicine, received skin care service occasionally between 6 pm.-8 pm., spent 1000 baht for each service, received hospital information from friends, and used to get service from neighborhood beauty parlor. Factors that affected Influencing consumer behavior in choosing Skin careClinic at Chularat Hospital 1 were hospital personneland service procedures.Factors that affected marketing mix Influencing consumer behavior in choosing Skin careClinic at ChularatHospital 1 were in high level of the opinion. Factor of personal difference, such as average income affected consumer behavior in choosing hospital at significant 0.05 level. Factors of marketing mix correlated with consumer behavior in choosing Chularathospital, such as personnel aspect, treatment services, rapid timely services procedures, and patient care.

Recommendations from this study were that administrative officers should have service strategy regarding quality of all services, patient care, adequate surgery equipment for all patients, and increasing number of personnel to provide service that appropriated with number of patients in order to handle patient requirement and rapidly services.
\end{abstract}

Keyword: marketing Behavior

\section{Introduction}

The appearance of Skin care clinics offers skin and facial care only. Skin careclinic has been very popular and increasingly interested by consumer who have been taken care of their appearances. Not only women are interested in skin care but men are as well. In the meantime, Thai people are concerned about their skin, appearance even though there is not wrong with it, but they always wanted to improve their looks to increase their personality. All kinds of people come in for this services treatment, such teenagers, adults, working people, college students who are interested in such a service. Students and teenagers cannot afford to pay high prices treatment but there are majority of consumer group which are the group that service providers are target to get for their businesses. As can be seen from the surgery clinics data have market share of 110,000 hundred thousand baht with the average rate of expansion 10 percent. (www.keajon.com).

The skin careclinic or Skin careclinic is an interesting business because of continued growth rate and behavioral health careof cultural skin careof International interests as mentioned regarding situation above, 
researcher is interested in studying marketing mix influencing consumer behavior in choosing Skin careclinic at Chularat Hospital 1 in order to bring this study to plan a guideline for service procedures.

\section{Concept, Theories of the Marketing Mix}

It deals with what a company is going to produce; how much it is going to charge; how it is going to deliver products or services to the customer; and how it is going to tell its customers about its products and services.

Traditionally, these considerations were known as the 4Ps — Product, Price, Place, and Promotion.As marketing became a more sophisticateddiscipline, a fifth ' $\mathrm{P}$ ' was added--People.More recently, two further ' $\mathrm{P}$ 's were added - Process and Physical evidence. Originallyformulated for the service industry, they arejust as important in other sectors.

In the 1990s, as experts realized that businesshad to become more customer-centric, analternative ' 4 Cs' of marketing was proposed.Correlating almost directly with the original 4PS,they were: Customer, Cost, Convenience andCommunication. The 7Ps model, however, hasendured and more than adequately incorporatestoday's customer-first marketing world.

\section{The Purpose of the Study}

1. To study Consumer Behavior in Choosing Skin care Clinic at Chularat Hospital 1

2. Marketing Mix Influencing Consumer Behavior in Choosing Skin care Clinic at Chularat Hospital

\section{Conceptual Frameworks of the Study}

As from the study above, research adapted marketing mix (7's P) theory of Philip Kotlerto use in conceptual frameworks in the study of Marketing Mix Influencing Consumer Behavior in Choosing Skin careClinic at Chularat Hospital 1 as follows:

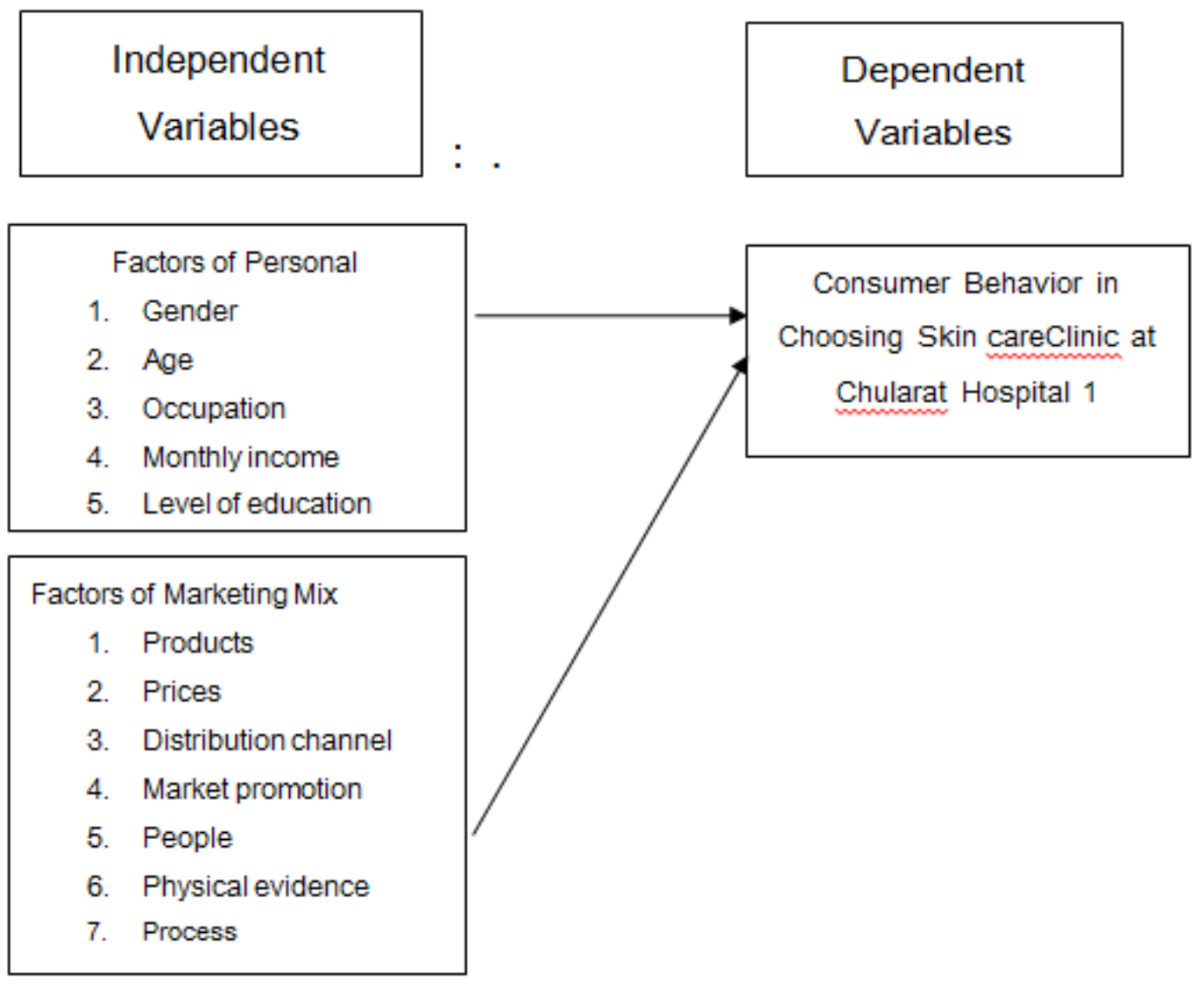




\section{Research Methodology}

\subsection{Sample Selection}

The samples were selected from 103 customers who were former customers of Skin careClinic at Chularat Hospital1

\section{Data Collection Procedure}

The questionnaires were distributed to sample of 103customers who were former customers of Skin careClinic at Chularat Hospital1. A total of 103 usable questionnaires were returned back to the researcher, yielding a 100 percent response rate and no missing data.

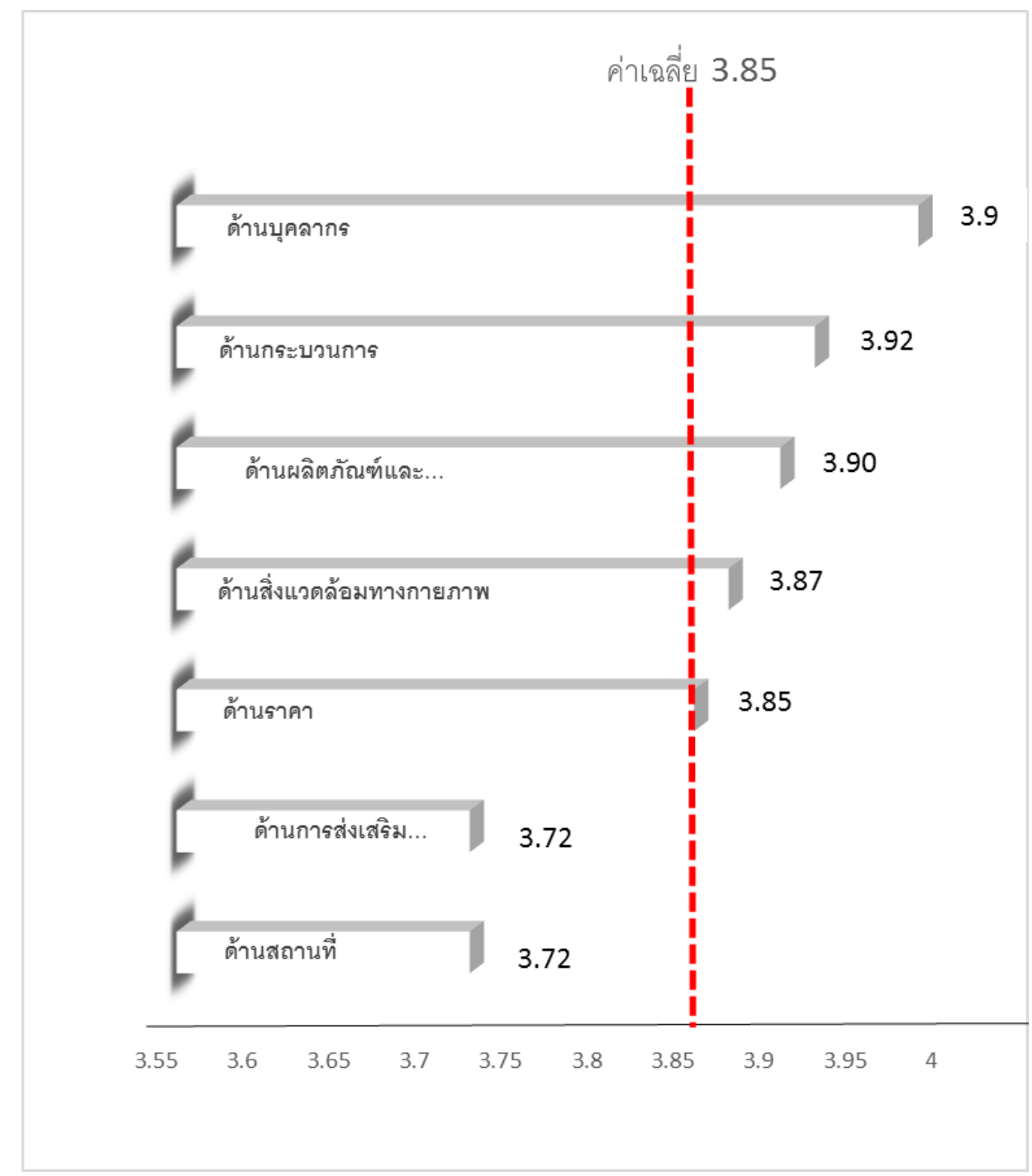

Fig. 1: The measurement of marketing mix analysis factors overview Illustrated as follows.

As from data above, findings revealed that the average picture of the opinion regarding of marketing mix factorsper consumer behavior in choosing Skin care clinic at Chularat Hospital 1 with details as follows: personnel aspect was in high level $(\bar{x}=3.98)$, service procedures aspect was in high level $(\bar{x}=3.92)$, products and services aspect were in high level $(\bar{x}=3.90)$, physical environment aspect was in high level $(\bar{x}=3.87)$, prices aspect was in high level $(\bar{x}=3.85)$, marketing promotion aspect was in high level $(\bar{x}=3.72)$, and place aspect was in high level $(\bar{x}=3.72)$, respectively. 
TABLE I: shows the results of hypotheses testing of variance of Consumer Behavior in Choosing Skin careClinic at Chularat Hospital 1, classified by gender.

\begin{tabular}{|l|c|c|}
\hline \multicolumn{2}{|c|}{ Gender } & \multicolumn{1}{|c|}{$\begin{array}{l}\text { Sig. } \\
\text { Square }\end{array}$} \\
\hline Consumer Behavior in Choosing Skin care Clinic at Chularat Hospital 1 & 13.825 & 0.181 \\
\hline Type of service & 15.186 & $0.010^{*}$ \\
\hline Choice of service & 3.766 & 0.584 \\
\hline Who influence in hospital selection & 14.164 & $0.003^{*}$ \\
\hline When to receive service & 0.362 & 0.985 \\
\hline What time to receive service & 5.800 & 0.215 \\
\hline How much each time when receive service & 7.001 & 0.135 \\
\hline What source of information & 5.418 & 0.144 \\
\hline Selected Skin care at Chularat hospital 1 & 2.818 & 0.831 \\
\hline How often to receive service & & \\
\hline
\end{tabular}

*Significant level $<0.05$

From table 1: the hypothesis testing revealed that variance of Consumer Behavior in Choosing Skin care Clinic at Chularat Hospital 1, classified by gender and when to receive service (Sig. $=0.010,0.003)$ at the statistical significant 0.05 level. As for personal difference gender, hour of service, cost of service, service information, and frequency to get service of Chularat Surgery hospital were greater than 0.05 levelmeaning no difference at significant level 0.05 .

TABLE II: shows the results of hypotheses testing of variance of Consumer Behavior in Choosing Skin careClinic at Chularat Hospital 1, classified by occupation

\begin{tabular}{|l|c|c|}
\hline \multicolumn{1}{|c|}{ Occupation } & \multicolumn{2}{|c|}{$\begin{array}{l}\text { Chi } \\
\text { Square }\end{array}$} \\
\hline Consumer Behavior in Choosing Skin care Clinic at Chularat Hospital 1 & 80.600 & $0.000^{*}$ \\
\hline Type of service & 43.136 & $0.002^{*}$ \\
\hline Choice of service & 35.870 & $0.016^{*}$ \\
\hline Who influence in hospital selection & 14.704 & 0.258 \\
\hline When to receive service & 19.185 & 0.259 \\
\hline What time to receive service & 56.917 & $0.000^{*}$ \\
\hline How much each time when receive service & 16.608 & 0.411 \\
\hline What source of information & 8.467 & 0.748 \\
\hline Selected Skin care at Chularat hospital 1 & 11.283 & 0.987 \\
\hline How often to receive service & \\
\hline
\end{tabular}

* Significant level $<0.05$

From table 2: the hypothesis testing revealed that variance of Consumer Behavior in Choosing Skin care Clinic at Chularat Hospital 1, classified by Occupation and when to receive service (Sig. $=0.000^{*}, 0.002^{*}$, $\left.0.016^{*}, 0.000^{*}\right)$ at the statistical significant 0.05 level. As for personal difference Occupation, hour of service, cost of service, service information, and frequency to get service of Chularat Surgery hospital were greater than 0.05 level meaning no difference at significant level 0.05 .

Table III: shows the results of hypotheses testing of variance of Consumer Behavior in Choosing Skin careClinic at Chularat Hospital 1, classified by level of education

\begin{tabular}{|c|c|c|}
\hline \multicolumn{3}{|l|}{ Level of education } \\
\hline Consumer Behavior in Choosing Skin care Clinic at Chularat Hospital 1 & $\begin{array}{l}\text { Chi } \\
\text { Square }\end{array}$ & Sig. \\
\hline Type of service & 47.821 & $0.021 *$ \\
\hline Choice of service & 30.831 & $0.009 *$ \\
\hline Who influence in hospital selection & 9.862 & 0.828 \\
\hline When to receive service & 19.968 & $0.018 *$ \\
\hline What time to receive service & 10.621 & 0.562 \\
\hline How much each time when receive service & 10.289 & 0.591 \\
\hline What source of information & 25.671 & $0.012 *$ \\
\hline Selected Skin care at Chularat hospital 1 & 14.660 & 0.101 \\
\hline How often to receive service & 30.844 & $0.030 *$ \\
\hline
\end{tabular}

* * Significant level $<0.05$

From table 3: the hypothesis testing revealed that variance of Consumer Behavior in Choosing Skin care Clinic at Chularat Hospital 1, classified by level of education and when to receive service (Sig. $=0.021 *$, $\left.0.009^{*}, 0.018^{*}, 0.002^{*}, 0.012^{*}, 0.030^{*}\right)$ at the statistical significant 0.05 level. As for personal difference level of 
education, hour of service, cost of service, service information, and frequency to get service of Chularat Surgery hospital were greater than 0.05 level meaning no difference at significant level 0.05 .

\section{Summary of Study Results}

On the basis of the results of this study, it could be concluded that most of 103 respondents were females (86 percent), age between $31-40$ years old (51 percent), private companies' workers ( 80 percent), bachelor degree graduated (37 percent), average monthly income 10,000-20,000 baht (41 percent).

The details regarding Consumer Behavior in Choosing Skin care Clinic at Chularat Hospital 1, such as cosmeceutical medicine spending (24 percent), Skin care (77 percent), self-decisionselected hospital choice (52 percent), used hospital service occasionally (45 percent), preferred hours of service $6 \mathrm{pm} .-8 \mathrm{pm}$. (39 percent), expenses each visiting 1,000 baht (36 percent), received hospital service from friends (47 percent), used service at neighborhood beautysalon ( 28 percent), and using the service at Chularat Hospital 1 for average of 4 times monthly.

\section{Summary of aspects of Marketing Mix Factors}

Summary of aspects of marketing mix influencing consumer behavior in choosing Skin careclinic at Chularat Hospital 1 revealed that the average picture of opinions was in the high level. Emphasized on personnel and services procedures with highest of opinion. Factors of products and prices, places, marketing promotion, and physical environment, with the average of opinion was in medium level as following details:

Products and services aspect, the average picture of opinions were in the high level which respondents emphasized on medication without side effect, trusted, and clinic dedicated in the field.

Prices aspect, the average picture of opinions were in the high level which respondents emphasized on easy separately payments, reasonable prices, and expense detail before service, respectively.

Marketing promotion aspect, the average picture of opinions were in the high level which respondents emphasized on additional service such as massage, discount prices, and information brochures.

Personnel aspect, the average picture of opinions were in the high level which respondents emphasized on competent surgeon, sale representative service, and expert treatment personnel, respectively.

Physical environment aspect, the average picture of opinions were in the high level which respondents emphasized on hospital reputation, surgeon with specialized in the field, and hospital cleanliness.

Service procedures aspect, the average picture of opinions were in the high level which respondents emphasized on service satisfaction, patient care, and rapidly services, respectively.

\section{Recommendations from this Study}

Recommendations from this study were that administrative officers should have service strategy regarding quality of all services, patient care, adequate surgery equipment for all patients, and increasing number of personnel to provide service that appropriated with number of patients in order to handle patient requirement and rapidly services.

\section{Suggestions for Future Research}

Suggestions for future research that administrative officers should study on Marketing Mix Influencing Consumer Behavior in Choosing Skin careClinic at Chularat Hospital 1 which is another service that hospital offer, this will be benefited to the hospital.

\section{References}

[1] KanogwanThongruen. (2555). Factors effecting consumer on selecting of skin careclinic in Saraburi Province, Marketing department, Business Administration Department, Technology RatchamongkolUniversity,publisher, Thunyaburi.

[2] Nada Pratumtong. (2554). Word of mouth of communication expectation and knowledge given to customer of Vuttisakskin careclinic, Master of Business Administration, Srinakarinviroj University. 
[3] ThongpornSaenakul\&SuthawanJeeraphun. (2554). Consumer behavior of skin careclinic in ChiengRai Province, Business Management Department, University of Thai Chamber ofCommerce.

[4] NarinthornChomchuen. (2556). Factors of Marketing Mix Influencing Consumer Behavior in Choosing Skin careclinic, Master of Business Administration, Bangkok University.

[5] PloypilinSapaopan. (2554). Factors of consumer satisfaction of skin care clinic in Bangkok Noi, Cosmetic science department, Mae FahLuang University.

[6] VassanaPanich\& Associate. (2552). Factors of marketing mix influencing consumer selection ofSkin careclinic in Bangkok, Marketing department, RatchaphatChankasem University.

[7] Kotler, Philip (2012). Marketing Management. Pearson Education. p. 25.

[8] Booms, Bernard H.; Bitner, Mary Jo (1981). "Marketing Strategies and Organization Structures for Service Firms". Marketing of Services. American Marketing Association: 47-51. 